\title{
Polysemiasta $^{1}$
}

Jos joku joutuu keskustelemaan maallikkojen kanssa - tarkoitan tässä ns. lukeneistoonkin kuuluvia ei-lingvistejä - jonkin sanan monimerkityksisyydestä, havaitsee heidän tavallisesti pitävän sitä kielen heikkoutena ja vieraasta kielestä puheen ollen sen oppimista suuresti vaikeuttavana seikkana. Kauhistellaan esim. englannin sanakirjaa selailtaessa saman sanan ällistyttävän lukuisia erilaisia käytäntöjä. Onhan esim. engl. play-sanalla (joka kuten tunnettua juontuu ranskan kautta lat. placere-verbistä) tavallisten koulusanakirjojenkin mukaan verbinä ainakin 10 erilaista intransitiivista ja 8 transitiivista merkitystä ja samavartaloisena substantiivina vielä 5 muuta merkitystä. Tämän verbin suom. vastineina luetellaan $\mathrm{mm}$. seuraavat: leikkiä (ilakoida, ilvehtiä), hypähdellä (liihotella, väikkyä, vivahdella), toimia, olla käynnissä (koneista), hyökätä (suuntautua, kohdistua), pelata (korttia), olla tekevinään (muka tehdä, tehdä leikillään), näytellä, soittaa, lyödä pallo omaan porttiin (kriketissä), käyttää hyväkseen, imarrella, olla hartaasti mukana. Fikä tämä esimerkki ole suinkaan mikään poikkeuksellinen laadultaan, päinvastoin: sellaisia voi sanakirjasta poimia sadoittain. Omassa kielessään suomalainen maallikko ei tietenkään tule yhtä helposti ihmetelleeksi samaa ilmiötä. Mutta kun hänen huomiotaan joskus sattuu kiinnittämään esim. se, että suomen laske $\varepsilon$-verbin ns. teonnimi lasku merkitsee aivan eri asioita yhdyssanoissa laskuoja, lasknoppi, laskulomake, laskukausi, niin hän on helposti valmis pitämään tällaista sekamelskaa itse asiassa primitiivisenä piirteenä, epäkohtana josta olisi pyrittävä vapautumaan, jos se vain olisi mahdollista.

1 Esitetty keskustelun alustuksena Turun yliopiston suomen kielen ja suomalàis-ugrilaisen kielentutkimuksen lisensiaattiseminaarissa 23. 3. 1965. 
Kielen tietoinen ohjailu onkin varsin usein kohdistunut jonkin sanan monimerkityksisyyden eli polysemian vähentämiseen. Oman kielemmekin historia tuntee tästä esimerkkejä: on keinotekoisesti erotettu kirja ja kirje, kasvu ja kasvi, taito ja taide, hallitus ja hallinto (vieläpä hallinta), rikos ja rikkomus, verbit valaista ja valkaista (myös valistaa), erottaa ja erittä̈̈, asettaa ja asentaa. Jne. jne. Tällainen tahallinen eriytys eli differentiointi on tietenkin rikastanut kielessämme ei vain vivahteisuutta vaan myös perustavan tärkeiden semanttisleksikaalisten ilmaisimien pääomaa, kuten eräät juuri mainituista esimerkeistä jo todistavat. Mutta tämmöisten seikkojen pintapuolinen arviointi voi myös johtaa keinotekoisen kielenparantelun arvon liioitteluun. Meitä saattaa kyllä hieman omahyväisesti hämmästyttää, että suomen sanat tanssitaito ja tanssitaide ovat kumpikin ruotsinnettavissa termillä danskonst, ja nähtävästi meidän kielessämme 'taidon' ja 'taiteen' erossapitäminen onkin hieman kätevämpää kuin ruotsissa. Mitään kohtalokasta ilmaisukyvyttömyyttä ei sentään ruotsissakaan tässä kohden ole: erehdyksen uhatessa voidaan taitosanamme vastineina käyttää esim. termejä kunnighet tai färdighet, ja toisaalta konneksio auttaa ymmärtämään, milloin konst tarkoittaa 'taidetta' eikä pelkkää 'taitoa'. Mutta jos joku tekee sellaisesta engl.suom. sanakirjan artikkelista kuin äsken puheena ollut play sen päätelmän, että englanti on suomeen verrattuna onnettoman köyhä kieli, koska play-sanalle on lueteltavissa ainakin kolmattakymmentä suomalaista merkitysvastinetta, niin päätelmä olisi perin juurin erheellinen ja osoittaisi tekijässään tietämättömyyttä eräistä lingvistisen semantiikan perusasioista.

Yhtä hyvin kielentutkijaa kuin valistunutta maallikkoa askarruttavat jatkuvasti polysemia ja monet sen kanssa yhteydessä olevat ilmiöt. Seuraavassa koskettelen niistä muutamia.

Biologian paljastamalle yksilön- ja lajinkehityksen samansuuntaisuudelle on koetettu löytää rinnakkaistapauksia sosiaalisen ja șịs myös kielellisen kehityksen alalta. Tosin tuollaista rinnakkaisuutta juuri kielen kohdalla on mekaanisesti soveltamalla liioiteltu ottamatta huomioon, että lapsi ylen harvoin saa kehittyä ympäristönsä kielen vaikutuksen ulkopuolella. Mutta kriittisestikin arvioiden tuosta paralleeliudesta näyttää löytyneen kieltämättömiä merkkejä myös kielen kehityksessä. Niinpä RoMAN JAKOBSON on pienessä mutta mielestäni erinomaisessa teoksessaan Kindersprache, Aphasie und allge- 
meine Lautgeschichte (Uppsala 1942) varsin vakuuttavilta tuntuvin perustein osoittanut, että puhumaan oppiva lapsi toteuttaa ympäristönsä kielen äänteiden omaksumisessa samanlaista porrastuneisuutta kuin toisaalla eri kansojen kielten äännejärjestelmien rakenne. Niinpä lapsi oppii kaikkialla, missä asiaa on tutkittu, aina omaksumaan dentaaliklusiilin $t: \mathrm{n}$ ennen kuin palataaliklusiilin $k: \mathrm{n}$, samoin aina $t: \mathrm{n}$ ennen kuin dentaalisibilantin $s: \mathrm{n}$, aina labiaalisen takavokaalin $0: n$ ennen vastaavaa etuvokaalia $\ddot{o}$ : tä ja aina $u: n$ ennen $y:$ ä. Tähän havaintosarjaan on ilmeisesti lupa verrata sitä tosiasiaa, että minkään kansan kielen äännejärjestelmästä ei ole todettu palataalista $k$-klusiilia, jos samasta järjestelmästä puuttuu dentaalinen $t$, eikä $s$-sibilanttia, jos järjestelmästä puuttuu $t$, mutta että toisaalta on olemassa kieliä, joista puuttuu $k$ tai $s$ mutta joissa on $t$. (Mainittakoon, että afaatikoilta nuo äänteet vammaisuuden lisääntyessä katoavat päinvastaisessa järjestyksessä kuin ne lapselle ilmestyvät, siis $k$ ennen $s$ :ää, $s$ ennen $t$ :tä, $\ddot{o}$ ennen $o$ :ta, $y$ ennen $u$ :ta jne.) Kysymyksessä näyttää siis olevan eräänlainen absoluuttisen foneettisen vaikeusasteikon ilmeneminen hämmästyttävän yhtäläisenä lastenkielessä (peilikuvamaisena siis toisaalta afaatikkojen kielen rappeutumisvaiheessa) ja kokonaisen kansan kielen äännejärjestelmissä.

Jotain vastaavanlaista on havaittu myös semantiikan ja syntaktissemanttisten seikkain alalla. On jo pelkästään teoreettisestikin oletettavissa, että lapsen sanavarasto hänen kielenomaksumisensa varhaisvaiheessa on täysin jäsentymätön, olivatpa sitten kysymyksessä sanan ja grammaattisten muotojen funktiot tai sanaluokat ja lauseenjäsenet. Ja induktiiviselle tutkimukselle antaa tässä kohden metodista luotettavuutta se itsestään selvä tosiasia, että aikuiset eivät lapsen kielenomaksumisprosessin varhaisvaiheessa voi semanttisesti vaikuttaa häneen, koska heidän merkityksilläoperointinsa suuresti ylittää lapsen käsityskyvyn. (Asiahan on tietysti toisin foneettisten ja morfologisten vaikutusten kohdalla.) Niinpä seuraavanlaisilla Rudolf MERINGERin havainnoilla (Aus dem Leben der Sprache, Berlin 1908, s. 148, Heinz Kronasserin mukaan, Handbuch der Semasiologie, Heidelberg 1952, s. 88) voidaan katsoa olevan todistusarvoa. Eräs hänen lapsensa tarkoitti äännöksellä pupu (= popo) joko lyömis- tai putoamistilannetta. Toinen lapsi (15. kk:llaan) käytti ilmausta papp tarkoittamaan 'jauhopuuroa', mutta myös koko syömispuuhaa: papp merkitsi milloin puremis- ja nielemisliikkeitä. (joita äännös papp kai juuri 
yritti matkia), milloin lautasta joko tyhjänä tai puurollisena, milloin taas mielihyvää ennen syöntiä tai sen jälkeen. "Papp-äännökseen liittyneet runsaat mielteet (merkitykset) käsittävät kokonaisen ajallisesti pitkän tilanteen, jonka osat voivat työntyä etualalle kulloisenkin tarpeen tai assosiaatiolajin mukaan; näin tietysti etenkin nälän yhteydessä tai lautasta täytettäessä, kun lapselle näytetään puremaliikkeitä, kun suuta pyyhitään perusteellisesti tai vatsaa sivellään huomiota herättävästi. Kaikkia näitä osaseikkoja ilmaisee papp." Tarpeen mukaan sitten tuollaisesta sanoisiko sekakoosteisesta merkitysmöykystä lohkaista a osa kulloisenkin aktuaalin ilmaisutarpeen realisoimiseksi.

Tällaiset lapsenkielen jäsentymättömät til a n n e valta is e t semanttissyntaktiset kompleksit edustavat luultavasti aikuisten kielen jonkin varhaisvaiheen nykyistä paljon niukemmin jäsentynyttä "sanan" (tai yhtä hyvin minkä tahansa "syntagman" tai "grammaattisen kategorian") merkitystä. Tätä käsitystä nähdäkseni tukee se tosiasia, että lukemattomat n y k y k i e l e n sanojen polysemiatapaukset selittyvät luontevimmin juuri oletettaessa kompleksisia, tilannevaltaisia lähtömerkityksiä. Eikä näiden suinkaan tarvitse aina juontua edes miltään ikivanhoilta "alkukantaisilta" kausilta. Ajateltakoonpa vaikka suomen saada-verbiä. (Olen sitä aikoinani semanttiselta kannalta analysoinut eräässä esitelmässä, joka on julkaistu Äidinkielen opettajain liiton vuosikirjassa II [1954] s. 55-.) Sillä on ainakin 9 toisistaan selvästi erotettavaa merkitystä ${ }^{2}$ : saan =1) 'tavoitan, yhdytän': Sain lahjan. - 2) 'pyydystän, hankin': "Kova on kokko kourin saa'a, kynälintu kynsin syöä" (Kalev.). 3) 'minun on sallittua, luvallista': Saan mennä. Alivuokralainen saa käyttää talon puhelinta. - 4) 'minun täytyy': Sain lähteä tieheni tyhjin toimin. - 5) 'onnistun suorittamaan': Sain koneen käyntiin. Helteeltä en saanut nukutuksi. - 6) 'luon, synnytän': 'Viel' olin miesnä kuuentena... tätä maata saataessa, ilmoa suettaessa" (Kalev.) "Soa tuli, pimei on!" (Säämäjärvi). — 7) 'tulen (johonkin)': "Meni nurkasta tupahan, sai sisähän salvoimesta" (Kalev.). Virossa: Ta sai koju. - 8) 'tulen joksikin, sukeudun' (= saksan 'werden'): "Joko nyt minulle neiti, kun sai sampo valmihiksi?" (Kalev.). -

2 Nykysuomen sanakirja erottaa nïtä enemmänkin laajassa, mutta mielestäni hieman epäjohdonmukaisesti erittelevässä artikkelissaan. 
9) 'rupean, alan': "Sai käköset kukkumahan" (Kalev.). "Saakamme sanelemahan" (Kalev.). — Näistä merkityksistä 6 ensimmäistä ovat transitiivisia ja 3 viimeistä intransitiivisia. Merkityserot näiden äärimmäisyyksien kesken ovat niin suuret, että onkin noussut kysymys, eikö tässä ole sekaantunut toisiinsa kaksi aivan eri sanaa. Näin päätteli mm. Heikki Paasonen (Beiträge 203) verratessaan vain 'tulemista' merkitsevää suomen saada-sanaa eräihin samaa merkitseviin mordvan ja tšeremissin sekä jurakkisamojedin verbeihin. Erkki Itkonen on myöhemmin (FUF 30 s. 3-, 1949) huomauttanut mielestäni aivan oikein, että kysymyksessä olevia eri kielten sanueita ei sen paremmin merkityksen kuin muodonkaan puolesta tarvitse pitää eri alkuperää olevina. Paitsi ims. taholla myös volgalaiskielissä tavataan rinnan 'saamisen' ja 'tulemisen' merkitykset, ja esim. saksan kielessä ilmaistaan samoja toimintoja samakantaisin verbein: kommen 'tulla' ja bekommen 'saada'.

Mitä liittymäkohtia siis keskenään on merkityksillä 'saada' ja 'tulla'? Olen mainitussa esitelmässäni vastannut tähän: kaikesta päättäen yhtäläisyys on siinä, että kummassakin tapauksessa on puhe k o sketuks e e n pääsemisestä: sain lahjan = 'saavutin kosketuksen lahjaan', sain sisään salvoimesta = 'saavutin kosketuksen tuvan sisukseen'. Tämä ei ole sen kummallisempaa, kuin että ruotsin få 'saada' vielä 1500-luvulla tarkoitti myös 'antamista': ruotsin sanan alkumerkitys on ollut kompleksinen 'ottaa tai pitää kiinni' (Hellquist), ja kiinnipitoa on tietysti voinut esim. jotain esinettä toiselle ojennettaessa harjoittaa yhtä hyvin antaja kuin saaja. ${ }^{3} \mathrm{Ja}$ vastaavin tavoin voidaan varsin luontevasti selittää myös 'alkamisen', 'synnyttämisen' ja 'joksikin tulemisen' merkitysten esiintyminen samalla verbillä.

Jos sitten kysytään, miten tuollainen saada-verbissä ilmenevä polysemioituminen on käytännössä voinut toteutua, siihen on annettavissa täysin riittävä vastaus, joka on kauan ollut kaiken semanttisen tutkimuksen yhteisomaisuutta. Vastauksen ytimenä on tietysti se, että merkityksen muutokset eivät koskaan ole tapahtuneet irrallisessa sanassa, vaan aina sidoksissa lauseyhteyteen, ns. konneksiossa.

3 Sekä 'ottamisen' että 'antamisen' merkitykset tavataan niin ikään ruotsin giva ja saksan nehmen -verbisanueissa ynnä eräissä muissa ieu, sanapesyeissä (Hellquist s.v. giva). 
Hyvin tunnettua on myös, että konneksion dynaaminen vaikutus sanan merkitykseen ei suinkaan ole rajoittunut vain joihinkin kielen kehityksen varhaiskausiin, joihin voitaisiin projisioida noita Meringerin lapsenkielen papp-tapauksia. Tosin esim. saada-verbimme merkityskahtalaisuus 'accipere' ja 'venir'e' etäsukukielten todistuksen mukaan saattaa hyvinkin juontua vuosituhansien takaa (tuskin sentään mistään kovin primitiivisestä kehitysvaiheesta asti). Mutta meillä on kosolti esimerkkejä myös siitä, että konneksioiden aiheuttamaa semanttista eriytymistä, differentioitumista tapahtuu yhä niin sanoakseni silmiemme edessä ja edellyttämättä mitään lähtömerkityksen komplelssisuutta. Mainitsen tässä vain yhden esimerkin (jota olen enemmälti käsitellyt äsken mainitussa esitelmässäni, ÄOLV II). Suomen adverbilla vasta on muiden käytäntöjensä ohella kaksi toisilleen miltei vastakkaista merkitystä, nim. 'tulevaisuudessa, vastedes' ("Käykää vastakin!') ja 'lähimenneisyydessä, äsken, vastikään' ("Vasta virkaansa nimitetty"). Sekä lähi- että etäsukukielten avulla on voitu osoittaa, että kumpikin näistä merkityksistä on nuori, oman kielemme erikoiskehityksen aikainen, ja että vanhaa konkreettista merkitystä kuvastavat esim. yhdynnäiset vastamäki ja vastatuuli. Sellainen lause kuin "Hän tulee vasta kesällä" on alkuaan tarkoittanut: 'Hän tulee vastaisuudessa, tulevaisuudessa kesällä'. Tässä yhteydessä vasta voitiin kuitenkin ymmärtää myös tarkoittavaksi 'ei ennen kuin', joten se havaittiin käyttökelpoiseksi myös menneisyydestä puhuttaessa: "Hän t u li vasta kesällä" = 'ei ennen kuin kesällä'. Toisaalta sellaisista sanaliitoista kuin vasta äsken, vasta hetki sitten jne. tarttui ellipsin tietä vasta-adverbin yksinään merkitysvivahdus 'juuri äsken, aivan vähän aikaa sitten': "Vasta hän tästä läksi".

Semmoisia konneksioita kuin tuo "vasta kesällä", jossa vastaadverbin merkitys voidaan ilman muuta tulkita kahdella tavalla ( vedenjakajatapa usiksi: nehän sattuvat jonkin harjun laelle puhjenneen lähteen tavoin sijaitsemaan sellaisessa maastonkohdassa, josta kehityksen puro voi eri suuntiin viettävän rinteen houkuttelemana herkästi lähteä virtaamaan muuannekin kuin yhtäänne. Tällaiset vedenjakajakonneksiot — mitään varsinaista ter miä en ole niistä huomannut ennen käytetyn - ovat kyllä vanhastaan semantiikan tutkimuksen haluttuja tavoitteita, ja semmoisten löytäminen esim. murteista tai vanhoista kielenmuistomerkeistä on 
usein antanut tervetullutta vakuuttavuutta varsinkin etymologiselle dokumentaatiolle.

Jos jäsentymättömän lähtömerkityksen olettaminen semanttisety: mologisessa tutkimuksessa yleensäkin on paikallaan, niin varsinkin puheen ollessa vo imakkaasti tunnepito is ista sanoista. Koska olen sellaisista tapauksista jo vuosikymmenien mittaan monesti kirjoittanut (HANs SPERBERin tässä suhteessa käänteentekevää teosta Einführung in die Bedeutungslehre olen selostanut mm. kokoelmassa Sanojen sanottavaa, Tietolipas 16, v. 1958; vrt. Vir. 1941 s. 157-, 338 - ja 1942 s. 42-), en nyt kajoa enemmälti tähän merkitysopin lohkoon, niin tärkeänä kuin sitä yhä pidänkin lingvistiselle praktiikalle. Ehkä saan kuitenkin mainita yhden tyypillisen esimerkin. Suomen itämurteissa ja joskus niitä mukailevassa kirjasuomessakin haastaa-verbi on normaali 'puhumisen' ilmaisin ("Haastanpa vain, mitä kylällä olen kuullut"), ts. siinä ei ole havaittavissa mitään tunteenomaisia ns. saattomielteitä. Sitä vastoin sanan yleisemmät kirjakieliset merkitykset ovat jo hiukan affektipitoisiakin (NS:n mukaan): 'antaa haaste, kutsua velvoittaen tai vaatien kilpailemaan kanssansa', 'kutsua vastaajaksi tai todistajaksi oikeuteen, manata', 'koettaa synnyttää riitaa tms.': Haastaa kaksintaisteluun, käräjiin; haastaa tappelua. Mutta voimakkaan affektisia merkityksiä tavataan vanhassa kirjasuomessa, nim. merkitykset 'härnätä, uhmata' ja 'kieltää' ('Se Jumalatoin $\mathrm{h}$ a a sta $\mathrm{p}$ i site wanhurskasta, ja liambaans kiristele henen ylitzens", Agr. III 261 ; "ne ylimeiset papit . . o olit h a a s t a nue t Jesusen Nimeen sarnamast", Agrr. I 322). Havaitaan siis, että haastaa-verbin tunnelataus on vuosisatojen kuluessa vähentynyt (ns. 'tunnear'von kulumisen laki'), ja yksityiskohtainen tutkimus oikeuttaa meidät edellyttämään, että sanan kaikki nyt mainitsemamme käytännöt ovat irtautuneet jostakin 'kiivaan puhumisen', vieläpä todennäköisesti 'kiivaan puhisemisen' jäsentymättömästä, monifunktioisesta miellemassasta.

Mielenkiintoinen semanttisten ilmausyksikköjen kompleksisen tilannevaltaisuuden todiste kulttuurikielissäkin on se edellä jo esiin vilahtanut seikka, että saman verbin ns. rektio ${ }^{4}$ voi olla sekä tran-

- Termiä rektio on käyttänyt tarkoittamaan verbin merkityksen sitä ominaisuutta, että se on joko transitiivinen tai intransitiivinen, ainakin MoRITz REGULA runsastietoisessa käsikirjassaan Grundlegung und Grundprobleme der Syntax (Heidelberg 1951) s. 115. 
s iti i vin en että in transiti i vi n en. Engl. play-verbillä siis on ainakin 8 transitiivista ja 10 intransitiivista käytäntöä ja suomen saada-verbillä ainakin 6:n transit. merkityksensä ohella 3 intransit. merkitystä. Logiikan kannalta on oikeastaan hämmästyttävää, että esim. nykyruotsin koka merkitsee sekä 'keittämistä' että 'kiehumista' ja saksan brennen sekä 'polttamista' että 'palamista' ja että suomen puinaa on ruotsiksi joko 'trycka' tai 'väga'. Onhan rektion ero tällöin, kuten sanottu, yhtä räikeä kuin merkitysero 'saamisen' ja 'antamisen' välillä. Mutta - kuvaavaa kyllä — käytännössä ei tällaisestakaan merkityksen kameleonttimaisuudesta näy olevan mitään haittaa, koska sitä kaikki tuntemamme kielet hyvin sietävät - konneksio torjuu tehokkaasti väärinkäsitykset. - Ehkä on paikallaan tähdentää, että kaikki nykykielen rektiokahtalaisuudetkaan eivät suinkaan ole mitään muinaisperintöä. Voidaan helposti osoittaa, että esim. nykyisin kaksirektioiset suomen verbit painaa ja palata (murt. 'kääntää, käännellä') ovat vanhoja transitiiveja, jotka suhteellisen myöhään ovat saaneet intransitiiviset rinnakkaismerkityksensä. Toisaalta taas esim. verbit puhua ja ampua ovat päinvastoin alkuperäiseltä rektioltaan intransitiiveja ja vasta kielemme erikoiskehityksen aikana transitiivistuneet. Vrt.: "Puhu, tuuli purjehesen, ammu pielehen, ahava!" (Kalevala). Mutta ainakin periaatteellisesti hyvin vanhantyyppistä rektion muuttumisen lajia edustaa laajasta, eri kieliin ulottuvasta levikistään päätellen lukuisien ' $\mathrm{n}$ äk e m is e n', 'k a t s o m i s e n' ja 'h u o m a a m i s e n' ilmaisimien merkityksenkehitys, joka on noudattanut kaavaa 'loistaa (himmeästi), kuultaa' > 'näkyä' > 'nähdä, huomata' ja jossa siis rektion muuttumisen suunta on kulkenut intransitiivisesta transitiiviseen. Olen tätä suomen kielessäkin runsaasti edustunutta semantiikan ilmiötä aikaisemmin eri yhteyksissä käsitellyt (esim. Vir. 1942 s. 56-, 1945 s. 198-), joten tyydyn tässä viittaamaan vain pariin kolmeen esimerkkiin.

Tyypillinen tähän luettava tapaus on suomen murteiden hohtaa, jonka suhteellisen alkuperäistä merkitystä edustaa kirjakielinen käytäntö ("Liesi hohtaa punaisena", "Ei kaikki hopeaa, mikä hohtaa"). Lönnrotin sanakirjan lisävihko mainitsee sanalle merkityksen 'varsna (huomata)', mikä nykyisin vielä tunnetaan yleisesti eräissä kaakkoishämäläisissä murteissa; esim. Hollolasta ja Asikkalasta on pantu muistiin paitsi itse kantasanaa hohtaa 'huomata' sellaiset johdokset kuin hohto 'huomiokyky, ymmärrys' ("On vielä täyles hohlos", voi- 
daan sanoa vanhuksesta), hohtavai(n) 'kekseliäs, hoksaavainen', hohtamatoi $(n)$ 'huomaamaton, tyhmä'. On epäilemätöntä, että semanttinen kehitys on tässäkin käynyt 'loistamisen, helottamisen' merkityksestä aluksi 'näkymisen' ja vasta sitten 'näkemisen, havaitsemisen' merkitykseen, esim.: Silmät hohtavat = 'loistavat' > 'katsovat' > 'näkevät'. (Viittauksia vastaavanlaisiin merkityksenkehityksiin sekä omassa kielessämme että vieraissa kielikunnissa olen esittänyt mp. Vir. 1942 ja 1945.) ${ }^{5}$ Kiinnitän tässä huomiota kahteen varmaan tapaukseen. Suomen eteläkarjalaismurteissa verbi haalattaa (hoalattoa) tarkoittaa 'häämöttämistä' ("Päivä. jo vähä hoalattoa" aamun alkaessa koittaa) mutta myös 'himmeätä näkemistä' ("Mie vähä hoalatan", sanoi puolisokea mies). Viron verbi kumama Wiedemann 'schwach leuchten' ('kuumab natukese" = 'es dämmert'), 'nähdä hämärästi' ("Selle silmaga kuuman veel" = 'mit diesem Auge habe ich noch einen Lichtschimmer'). - Varmojen rinnakkaistapausten runsaus on tehnyt mahdolliseksi osoittaa erittäin todennäköiseksi, että myös suomen yleiskielen tärkeät verbit huomata ja havaita ovat kumpikin aikaisemmin merkinneet 'häämöttämistä, himmeää loistamista' ja vasta myöhemmin transitiivistuneet nykyiselleen. Tässä yhteyđessä on kiintoisaa todeta, että huomata ja havaita -verbeillä molemmilla murteittain tavattava merkitys 'herätä unesta, havahtua' on niiden merkityksistä myöhäisin ja kehittynyt juuri 'näkemisen, huomaamisen' merkityksestä, joten siis näiden verbien kohdalla rektio on vaihtunut kahdesti: intransitiivisesta transitiiviseen ja siitä jälleen intransitiiviseen, siis: 'kuultaa, häämöttää' > 'katsoo' > 'näkee, keksii' $>$ 'herää'.

Puheena olleita rektioseikkoja muistuttavat semanttisesti tapaukset, joissa aikaisemmin inkoatiivinen verbi on muuttunut essentiaaliseksi eli - kuten voitaisiin sanoa - on vaihtanut aspektia. Olen

s Mainitsen sivumennen, että akateemikko Y. H. Toivosen Suomen kielen etymologisen sanakirjan ensi vihkossa noudattamien periaatteiden mukaan esim. hohtaa-verbi oli jätettävä pois koko teoksesta, koska sillä ei ole vastineita sukukielissä (mikäli itäkarjalaismurteita ei pidetä sukukielinä) ja sille ei siis voida esittää. mitään "etymologiaa". Verbin erinomaisen mielenkiintoinen semanttinen kehitys omissa murteissamme jäi siis kokonaan vaille huomiota, vaikka se oli tieteellisessä kirjallisuudessa selitetty.

6 SKES :ssa on kyllä olemassa lyhyet artikkelit havaita ja huomata -sanoista, mutta semanttisen kehityksen edes viittauksenomainen selitys niistäkin puuttuu. Vrt. Rapola Vir. 1960 s. 31. 
joskus huomauttanut, siitä, että suomen asua-verbi, joka nykyisin aina on essentiaalinen, oli vielä 1600- ja 1700-luvullakin inkoatiivinen (Maskun Hemminki 1616: "Asu i... armon Auringo jäll Paistaman pacanan maall"; Ganander [sivukäsiala, Mynämäen murteesta]: "Pannu a s u u vuotamaan" = 'börjar på at rinna'), kuten asian laita yhä on viron kielessä "Ta a s u s töö kallale" = 'ryhtyi työhön'). - Istua ja nukkua ovat johtimestaan päätellen olleet alkuaan pelkästään inkoatiiviset, mutta ovat nykyisin yhtä hyvin myös essentiaaleja. Verbi viipyä, jonka -py-johdin niin ikään osoittaa sanan alkumerkitykseltään inkoatiiviseksi, esiintyy sellaisena vielä ainakin inkeriläisessä kansanrunoudessa: "Siih en vi p yi velvyeen, Kuningasta kutsu m a n" (so.: 'myöhästyi', VR IV: 2 n:o 2315, V. Porkka Hevaalta 1881-1883). Samaa voidaan todeta tämän verbin etymologisesta sukulaisesta viihty $\ddot{a}$ (vrt. syrj. vï 'ääri', unk. vég 'loppu'); sen varsinainen merkitys on NS:n mukaan 'tuntea olonsa jssak (ympäristössä tms.) miellyttäväksi, mukavaksi, tuntea olevansa jssak kuin kotonaan, mielellään, tyytyväisenä kaipaamatta sieltä pois': "Kotona viihtyvä lastenhoitaja" — siis selvästi essentiaalinen käytäntö. Mutta NS tietää myös, että viihtÿ̈ "vars. va n h. ja ylät." = 'tyyntyä, hiljentyä, rauhoittua': "Itkevä lapsi viihtyi saatuaan ruokaa"; "häly mainen viihtyy, taisto raukenee"; kuvaavaa on, että tämä merkitys on Lönnrotilla ensimmäisenä: "stillas, lugnas, tystna, upphöra a.tt gråta, få ro': "lapsi viihtyy rintaan" = 'barnet lugnas när det făr bröst'. Yhtenä "vedenjakajakonneksiona" on saattanut olla juuri jokin tuollainen "lapsi viihtyy", alkuaan = 'asettuu, tyyntyy', mutta tilanteen jatkuessa pitemmälti rauhallisena myös = 'on levollinen, tyytyväinen'. Elias Lönnrotin ja hänen aikalaistensa kielitajussa ilmeisesti täten kaksiaspektinen verbi viihty $\ddot{a}$ on nykykielessä taas vain yksiaspektinen, mutta aspekteista on tallella enää ainoastaan myöhäsyntyisempi, nim. essentiaalinen.

Sanoin, että maallikot helposti pitävän sanan monimerkityksisyyttä jonkinlaisena välttämättömänä pahana. Luulisin, että jo tässä ainakin välähdyksenomaisesti esiintulleet muutamat sanoisiko semanttisen biologian näkökohdat riittävät perustelemaan päinvastaisen käsityksen: polysemia on jokaisen luonnollisen kielen (en siis tarkoita mitään esperantoja) sanaston välttämätön ja sen tarkoituksenmukaisuutta suunnattomasti lisäävä, tekisi mieli sanoa nero- 
k a s ominaisuus. Ilman polysemiaa, siis jos jokaisella käsitteellä, mielteellä, merkitysvivahteella, ajatuksen ailahduksella täytyisi olla äänteellisestikin eriytynyt oma ilmaisimensa, kielen oppiminen olisi käytännössä ylivoimainen tehtävä ja täten sen kasvaminenkin tuollaiseen mielettömään rajattomuuteen mahdotonta. Ja toisaalta: ainoastaan polysemian olemassaolo tekee mahdolliseksi kielelle ominaisen herkän joustavan mukautumisen ihmisen sekä ajattelu- ja tiedotusvälineen että hänen henkisten saavutustensa säilyttäjän tehtäviin. Sama, mikä pätee sanan polysemiasta, pätee mutatis mutandis myös muoto-opin ja syntaksin kaikkien kategoriain monifunktioisuudesta.

Polysemiaakin luonnehtii siis roomalaisten mainiosti muotoilema oivallus: multum, non multa.

\section{Lauri Hakulinen: Einiges über die Polysemie}

Im Gegensatz zu der häufigen Annahme der Laien ist die Polysemie ein notwendiger, ja sogar ein bewundernswürdig zweckmässiger Zug in der Systematik einer jeden Sprache. Der Verfasser beschäftigt sich im Licht finnischer Beispiele mit einigen Prozessen, die zu lexikaler Polysemie geführt haben. In seinem kleinen, aber ausgezeichneten Werk "Kindersprache, Aphasie und allgemeine Lautgeschichte" (Uppsala 1942) hat Roman Jacobson aufgezeigt, dass Erscheinungen, die mit der aus der Biologie bekannten onto- und phylogenetischen Parallelität nah verwandt sind, auch in der Phonologie der Sprache beobachtet werden können, wenn man die Entwicklung der Kindersprache und die Lautstruktur der Sprachsysteme der Völker miteinander vergleicht. Etwas Entsprechendes wurde auch in der Semantik festgestellt. Der Verfasser erwähnt die von Rudolf Meringer (Aus dem Leben der Sprache, Berlin 1908, S. 148) genannten Beispiele über die situationsgebundene Komplexität der Ausdrücke der Kindersprache, denen auch Heinz Kronasser Beobachtung schenkte (Handbuch der Semasiologie, Heidelberg 1952, S. 88). Derartige Ausdrücke vertreten wahrscheinlich irgendeine sehr frühe Phase der Erwachsenensprache. Darauf weist indirekt auch der Umstand hin, dass viele Fälle von Polysemie in der modernen Sprache am besten gerade durch die Annahme solcher situationsbedingten, komplexen Ausgangsbedeutungen erklärt werden können. Der Verfasser nennt als Beispiel das fi. Verb saada; dies besitzt mindestens 9 verschiedene Bedeutungen, deren entfernteste, 'venire' und 'accipere', so weit voneinander abweichen, dass sogar vermutet worden ist, die Etymologie der Verben saada 'venire' und saada 'accipere' sei versehiedenen Ursprungs. Der Verfasser vertritt die Ansicht, beide Bedeutungen hätten sich aus einer komplexen Grundbedeutung heraus entwickelt: '(mit etwas) in Berührung kommen'. In anderem Zusammenhang ist schon früher 
darauf hingewiesen worden, dass die deutsche Sprache eine entsprechende Parallelerscheinung besitzt: kommen 'venire' und bekommen 'accipere'. (Siehe: Äidinkielen Opettajain Liiton vuosikirja [Jahrbuch des Verbandes der Lehrer der Muttersprache] II, Riihimäki 1954, S. 55-.) Es ist nicht immer nötig, in der fernen Vergangenheit nach den Quellen derartiger Polysemien zu forschen; auch in der modernen Sprache können immer noch durch verschiedene Konnexionen logiseh sogar völlig entgegengesetzte Bedeutungen eines und desselben Wortes entstehen. Als Beispiele erwähnt der Verfasser die fi. Arverbien vasta 'eben, in der jüngsten Vergangenheit' (vasta kirnuttu voi = 'frisch gebutterte Butter') und vasta 'in der Zukunft' (Käy talossa vastakin! = 'Besuche uns nächstens wieder!'), deren doppelte Bedeutung er schon früher erklärt hat (oben erwähntes Jahrbuch, S. 58). Die Rektion eines Wortes verändert sich aufgrund der versehiedenen Konnexionen leicht aus einer transitiven in eine intransitive (z.B. painaa 'drücken' $>$ 'wiegen', palata 'wenden' $>$ 'zurückkehren') oder umgekehrt (ampua 'geschleudert werden' $>$ '(er) schiessen', puhua 'ausdünsten, ausatmen' $>$ 'sprechen', hohtaa 'schimmern, strahlen'> dial. 'beobachten, wahrnehmen', haalattaa dial. 'dämmern, schimmern' $>$ 'sehen') oder aueh aus einer intransitiven in eine transitive und wieder zurück (havaita und huomata 'schimmern' $>$ 'beobachten' $>$ dial. 'erwachen'). Die Verschiedenheit der Konnexionen hat auch oft zu einer Veränderung des Verbaspekts geführt (inchoativ > essential, z.B. istua 'sich setzen' $>$ 'sitzen', nukkua 'einschlafen' $>$ 'schlafen', asua 'sich auf etwas einlassen' $>$ 'wohnen', viihtyä 'sich legen, still werden' $>$ 'gedeihen, sich wohl fühlen', vïipyä 'sich verspäten, wegbleiben' $>$ 'dauern, verweilen'). Manche der so entstandenen verschiedenartigen Bedeutungen ein und desselbeu Wortes existieren in der Sprache oder im Dialekt nebeneinander, ohne dass dadurch irgendwelche Störung entsteht. 